\title{
LA ILUSIÓN DEL RETORNO
}

\section{Daniela Bachi*}

He visto a la Historia en una bandera negra
que camina y avanza como un bosque
pero no anoté la fecha, vivo en la añoranza,
el fuego, la rebelión, en la magia
de su veneno creador.
Mi patria es esta centella,

Adonis, Éste es mi nombrel

\section{Del Folketeatret a Levante}

\section{Los primeros años de la década de}

1990 dieron inicio a un conjunto de negociaciones diplomáticas; entre éstas, la que despertó mayor esperanza fue Oslo. Al menos en apariencia, el país de los Acuerdos de Oslo celebra el pluralismo cultural al abrigar una extensa comunidad de inmigrantes que ingresaron al país sin papeles, pero cargando consigo muchos recuerdos. ${ }^{2}$ Frente a la entrada principal del Folketeatret de la capital noruega, se encuentra

* Relaciones Internacionales, ITAM.

${ }^{1}$ Adonis (Ali Ahmed Said Esber), Árbol de Oriente. Antología poética, 1957-2007, 2010, Madrid, Visor Libros, edición de Federico Arbós, p. 173. El siguiente relato nace del deseo de desentrañar y realizar las conexiones pertinentes entre una serie de experiencias que comenzarían en Siria, Líbano y Jordania, en junio de 2010 -en el marco de un proyecto de viaje comunitario realizado por un grupo de quince estudiantes de las licenciaturas en Relaciones Internacionales y Ciencia Política del ITAM, en colaboración con la Agencia de Naciones Unidas para los Refugiados Palestinos en Oriente Próximo (UNRWA, por sus siglas en inglés)y que, sin proponérselo, concluirían en Oslo un mes después. El proyecto de viaje comunitario fue organizado por la doctora Laura Rubio Díaz Leal, en estrecha colaboración con el maestro Diego Gómez-Pickering y el doctor Pedro Cobo. Extiendo a los tres mi más profundo agradecimiento por dar vida a esta experiencia.

${ }^{2}$ En 1951, la UNRWA definió como refugiado beneficiario de su asistencia a toda aquella persona cuyo lugar habitual de residencia era Palestina, entre junio de 1946 y mayo de 1948 y que, como consecuencia del conflicto de 1948, perdió su vivienda, tierras u otras propiedades y medios de vida. Asimismo, la definición aclara que los descendientes directos de los refugiados registrados en la Agencia también son elegibles para recibir su asistencia. 
un pequeño local que difícilmente pasa inadvertido a la mirada del transeúnte curioso. Un letrero colocado sobre la cornisa de la puerta ondea con letras rojas un radiante Salam Habibi. Desde la primera noche en Oslo me adentré en el local de la céntrica avenida Storgaten, quizás con el pretexto de saciar un arrebato de nostalgia que me hacía añorar, desde hacía un par de semanas, el sabor de la cocina levantina. O quizás con el afán de encontrar una puerta a Oriente próximo, inmersa entre todo ese remanso de posmodernidad.

El ambiente parecía apropiado para entablar una conversación con ánimo de elogio al pueblo palestino; elogio del cual termina desprendiéndose, de manera casi invariable, la denuncia. Representaciones de beduinos en su travesía por el desierto y retratos del Che Guevara apilados entre las demás imágenes de mártires de la guerrilla fida ’yyi tapizaban las paredes, pero los anuncios no habían sido colocados con el propósito de publicitar la última sensación teatral al otro lado de la avenida. A los panfletos que exaltaban a los héroes románticos de la iconografía nacional palestina se les sumaban los anuncios de promoción turística. La mezquita del Domo de la Roca-desde donde Mahoma se habría embarcado en su milagroso viaje nocturno hacia el paraísosobresalía dentro del top ten de los lugares que merece la pena visitar durante una jornada turística en el corazón de esta tierra. El techo del local se encontraba ornamentado con banderitas en tonos negro, rojo, verde y blanco, que, en sus diferentes combinaciones, forman la mayoría de las insignias nacionales de los países árabes; eso sí, hay que reconocer, en consonancia con su clientela más habitual. Y es que, entre las comunidades de refugiados palestinos que han llegado al país huésped acariciando la posibilidad de disponer de un feliz porvenir, la reproducción de una atmósfera con símbolos, materiales, iconografías e imágenes míticas de su tierra de origen es la manera de mantener vivo su vínculo con el pasado y sobrepasar la experiencia del exilio.

Un par de horas más tarde, del más alejado de los puestitos improvisados en la plaza localizada en la trastienda del Folketeatret colgaba un discreto letrero que anunciaba: "Palestinas de Hebrón". Al finalizar 
una de las cinco oraciones del día, el señor al frente del tenderete recogió el tapetito que había acomodado cuidadosamente sobre el pavimento en dirección a la Meca. Ahí, en medio del mercado - ahora transformado en bazar-me encontré buscando, casi instintivamente, la media luna en el ápice de alguna torre entre los edificios erigidos en el horizonte. No había mezquitas. No había minaretes. No había muecín, ni la melodía de algún canto evocativo. Frente a mí, en cambio, quedaba el movimiento armónico de las gaviotas sobrevolando un paisaje imperturbable. Con frases nítidas y contundentes, Ayid Ishqair repasa la historia de su vida antes de su llegada a Oslo, misma que se anima a describir como un continuo deambular. De Jordania adquirió el segundo documento de viaje que le permitiría cruzar las fronteras que traspasó durante los años posteriores a la hégira de su natal Hebrón. "Dígame Ayid -le pregunté entonces- ¿qué aspectos de su identidad ha tenido que cambiar desde que llegó a Oslo?" "Ninguno -contestó con tono solemne- yo nunca transformaré mi identidad. Permaneceré aquí como palestino. De existir alguna amenaza en contra de este país, mis hijos y yo estaremos en la frontera para defenderlo. Pero por ningún motivo me olvidaré de mi tierra".

La segunda noche en Oslo volví al local en Storgaten. El joven iraquí que enrollaba las bolitas de garbanzo dentro del pan árabe, preguntó: “¿Salsa tradicional o picante?”. "La picante” —respondí esbozando una sonrisa mientras rememoraba el fantástico encuentro entre las tradiciones culturales levantinas y un toque de mexicanidad. Esta vez, el falafel atrajo de manera inmediata los recuerdos del campamento de verano para niños refugiados palestinos e iraquíes en Kafar Sita, una villa situada en la provincia siria de Tartús.

\section{El ritmo arrebatador de Kafar Sita}

En Kafar Sita, los niños se despedían del nado y el Mediterráneo estaba hecho un resplandor cuando Najah Zaghmout, directora del cam- 
pamento, me ofreció una silla a la orilla de la playa. A mi llegada transcurría ya una animada conversación entre Najah, Qassem, traductor oficial del campamento, y Shadi, un joven voluntario de espíritu infatigable. El café y las pepitas en el plato que me extendió la imponente directora tenían el sabor de la auténtica hospitalidad. Qassem, "el cubano", nació en Siria pero aprendió español cuando estudiaba ciencia política en La Habana. Confiesa su afinidad por la cultura de los países latinoamericanos y una especial devoción por las figuras revolucionarias. Y es que la lucha revolucionaria latinoamericana (de inspiración cubana) coincidió con los años en los que el movimiento revolucionario palestino, Al Fatah, comenzó a reclutar militantes en los campamentos de refugiados. Al Fatah pretendía transformar a los refugiados palestinos de 1948 en personas que tomaran conciencia de su destino colectivo, dando inicio a la lucha por la liberación nacional $\mathrm{y}$, en el proceso, buscando su transformación de refugiados desdeñados en revolucionarios orgullosos que pelearan por la liberación de su tierra. ${ }^{3}$ Para Qassem, el Che simboliza la resistencia y la rebelión en su lucha por alcanzar la justicia social y dejar atrás un pasado común de humillación y opresión. Describe lo que a su juicio asemeja los movimientos revolucionarios latinoamericanos y los palestinos: "pueblos

144 que no se dan por vencidos frente a la invasión de las potencias coloniales; conscientes de la herencia cultural que llevan consigo; acechados por el que propaga una imagen degradante y ajena a su identidad". De su boca fluyen nombres que los adversarios designan a uno y a otro: "flojo, mafioso y sucio... terrorista, fundamentalista y ladrón... ¿Más café?" - concluye el cubano.

Ser un niño palestino en un campamento de verano tiene algo de ingenuidad fusionada con consignas de lucha política; de espontaneidad contrastada por un automatismo que se acelera mediante dos engranes: la memoria colectiva sobre las injusticias históricas y las referencias del exilio por nacimiento. Está prohibido vivir sin los referentes de un

${ }^{3}$ Helga Baumgarten, "The Three Faces/Phases of Palestnian Nationalism, 1948-2005", en Journal of Palestine Studies, 2005, vol. 34, núm. 4, p. 33. 
pasado de despojo y privación. Se espera que experimenten la nostalgia por la pérdida de un hogar que nunca habitaron; que extrañen con vehemencia esa tierra mítica que jamás conocieron, pero que muy poco importa, porque aun sin haberla visto, continuarán relatando lo hermosa que era.

En Kafar Sita, los narraciones de las primeras generaciones de refugiados cobran vida con las expresiones artísticas de los niños. No obstante, la dificultad de descifrar su autenticidad tiene que ver con la tenue línea divisoria, cuando existente, entre las muestras de expresión creativa y los ejercicios de propaganda. ${ }^{4}$ A fuerza de repetición, los mitos cooptan los gustos y las sensibilidades de los jóvenes para transmutar recuerdos lejanos en expresiones palpables de la realidad. Los dibujos de las mezquitas, las efigies nacionales, las banderas y los mapas delineados con las fronteras de 1948 son el medio para abrirse camino en el asedio. De nuevo, inundan los matices en negro, rojo, verde y blanco. Vuelve a resplandecer la cúpula dorada de la mezquita del Califa Abd-al-Malik en Jerusalén, pero esta vez con pinceladas rebeldes sobre enormes cartulinas, voluminosa en figurillas de barro o grabada sobre la fina arena de la playa. Con el afán de mantener viva la memoria histórica y rendir tributo a sus antepasados, las representaciones más trágicas muestran el allanamiento como consecuencia de la guerra: el ajetreo de los tanques, la falta de los padres, la catástrofe en el pueblo idílico en donde sus abuelos solían habitar y otras imágenes que se suman al repertorio de experiencias de pérdida. El pasado idealizado es desplazado con la llegada del victimario, quien abre paso a un presente invadido por penas.

El Mediterráneo llama a una inmersión en las olas por la mañana y a otra por la tarde. Por lo menos una treintena de niños provenientes

${ }^{4}$ La politización de la cultura en torno a la noción del retorno se distingue de manera particular en el caso palestino si se compara con otros casos de migración y diáspora. Para las comunidades de refugiados palestinos, el arte y la cultura se encuentran enraizados en la lucha por la liberación nacional. Ver Adila Laïdi-Hanieh, “Arts, Identity, And Survival: Building Cultural practices in Palestine”, en Journal of Palestine Studies, 2006, vol. 35, núm. 4, p. 39. 
de Irak había experimentado ya la sensación de la arena, pero no la de la suave mezcla que se forma con el agua, sino la que con el viento se torna insoportable bajo las precarias condiciones de vida en los campamentos del desierto de Al Tanf y Al-Hol, situados en la frontera entre Siria e Irak. Durante y después de la invasión estadounidense a Irak, las familias de los niños de origen palestino fueron blanco de violencia sectaria, limpieza étnica, asesinato selectivo y secuestro perpetrado por milicias y otros grupos armados. El contingente de refugiados iraquíes que llegó a Al-Tanf vivió en el limbo durante cuatro años, en una franja de tierra que no pertenecía ni a Siria ni a Irak. No se les permitía la entrada a Siria y temían regresar a Irak, donde estarían expuestos a la persecución por parte de grupos armados, kurdos y chiítas, que todavía los acusan de ser partidarios de la insurgencia sunita y que están resentidos por los privilegios concedidos a los palestinos durante el régimen de Sadam Hussein. ${ }^{5}$

Mientras tanto, en Kafar Sita se experimentaba ligereza y felicidad sin límites, al gritar “;Yallah!... ;Yallah!” mientras formábamos un círculo y dábamos vueltas frenéticas entre las olas. Cicatrizaban con ardor fugaz las heridas, al tiempo que reconfortaba sentir la arena segura ahí, debajo de los pies, y la superficie del agua saludando y despidiendo los tobillos. Dentro del mar, antes respetado con miedo reverencial, se vencía una especie de temor acelerando el ritmo, con la risa de los niños a lo lejos repitiendo la misma cantaleta, “'Yallah!, ¡Yallah!’, una, otra y otra vez.

En la Siria costera, todo apunta a que el estado de ánimo general se encuentre sujeto a los caprichos que depara la hora del día. Desde el

${ }^{5}$ Entre los privilegios, se cuenta la política que garantizaba a los palestinos vivienda subsidiada a expensas de propietarios chiítas, a quienes el gobierno iraquí pagaba una miseria a cambio de la renta de una finca; la exención de servicio militar para los jóvenes palestinos, y la formación de una fuerza paramilitar (Jaysh al-Quds) con el objetivo de "liberar" Jerusalén, que obligaba a jóvenes kurdos y chítas a adherirse como voluntarios, sin hacer lo mismo con los propios palestinos. 
amanecer hasta el atardecer las actividades en el campamento discurrían con naturalidad y un aire candoroso. En punto de las nueve, el sonido que conducía a las almas a un estado de arrobamiento era el que acompañaba al dabkeh, el baile folklórico.

Cae la noche en Kafar Sita y todos forman una unidad al momento de abrazar los ritmos. Brazos arriba, muñecas ondeantes y cuerpos girando de prisa sobre órbitas con los tobillos, balanceándose hacia fuera, conforman un caleidoscopio difícil de reproducir en el imaginario occidental. Primero derecha y luego izquierda. Una pierna se desliza con soltura inusual hacia atrás y los hombres se toman por los hombros formando una rueda.

Cae la noche en Kafar Sita cuando la presencia de un visitante irrumpe en el escenario. No se sabe si vendrá a amenizar el ambiente, preparado con antelación para impresionar al observador atento. La música es estremecedora y la fuerza de los bailes desafiante. Vivo en la añoranza, el fuego, la rebelión, en la magia de su veneno creador... La disciplina, el orgullo nacionalista y un profundo sentido de sacralización moldean las cadencias del cuerpo e incluso los gestos.

Cae la noche en Kafar Sita y se abre una brecha en el mundo infantil para dar paso a uno de realidades agrias, en el que se recuerda no sólo al antagonista del relato, sino también los abusos, las humillaciones y las fechas. La música se apaga de golpe para abrir espacio a un discurso que gravita cerca de la retórica incendiaria. Silencio. "Más de treinta nacionalidades a bordo de la flotilla de la libertad. Activistas a bordo y navíos de ayuda humanitaria agrupados ese día frente a las costas de Gaza", declamó un señor con incisivos ojos verde pálido. "La flotilla pretendía desafiar el asfixiante bloqueo que mantiene en la miseria a nuestros hermanos en Gaza". El periodista describe a detalle el sangriento asalto a la flotilla de la libertad, que tuvo lugar apenas un par de semanas atrás. Hacía falta imaginarlo así: el ensordecedor golpeteo de las olas sobre el casco. La luz que se acerca. El olor del miedo. El odio en busca de un enemigo. El pánico de las voces con el crujir de las armas. 
Las imágenes avanzan como un gran cauce que, lejos de condenar con dureza la guerra, reafirman la voluntad por delimitar las bifurcaciones. Al finalizar el número del periodista, los más pequeños se despiden para ir a la cama mientras los demás continúan reviviendo mediante los bailes el imaginario heroico. Las palabras también descansan complacidas por lograr repartir, una vez más, los papeles asignados: opresor, enemigo y victimario.

\section{En un oasis damasceno}

Nuestro usual punto de partida y retorno, una típica casa damascena a la orilla de los muros de la Ciudad antigua -en donde el espeso aroma del narguile y del té desvanecían los pensamientos para abrir paso a un nuevo mundo de sensaciones-, fue el lugar idóneo para tener un encuentro con Saleh Almani: reconocido traductor y especialista en literatura hispanoamericana. Obras literarias como las de Juan Rulfo, Carlos Fuentes y Alberto Ruy Sánchez forman parte de las más de ocho decenas de puentes que Saleh ha logrado tender entre la literatura hispanoamericana y la árabe. Almani también es refugiado palestino. Con

148 el penetrante canto del muecín como música de fondo, relata que todos sus amigos de la infancia eran huérfanos. Recuerda que en la sangre de los palestinos corre la añoranza de volver a esa memoria enraizada sobre sus hogares antes de la primera $N a k b a,{ }^{6}$ congelada en la historia de un pasado que ellos aún piensan libre de escombros. Entre la plática literaria se cuelan opiniones políticas en torno al conflicto palestino-israelí. "En Israel sólo se habla de seguridad, pero, ¿de quién?" Saleh no calla su indignación frente a la arrogancia de aquellos que se muestran indiferentes a la privación de los derechos y la marginación de millones de individuos. "Israel ocupó un territorio para hacer una nación en nombre de una religión, pero, ¿qué democracia es esa?” -reprende Saleh- ¿Qué democracia trata a las minorías como ciudadanos de segunda clase?

${ }^{6} \mathrm{Nakba}$, o catástrofe, es el término que los palestinos usan para referirse a su propia dispersión después de la creación del Estado de Israel. 
A tono, cabe recordar que la posición oficial israelí se ha manifestado reiteradamente en contra de un acuerdo que contemple la repatriación a gran escala de los refugiados palestinos al territorio de Israel, proponiendo como alternativa su reasentamiento en países árabes o en terceros países. Hoy, el número de refugiados registrados en los sitios en los que la UNRWA ejerce su acción asistencial alcanza los cinco millones. ${ }^{7}$ Si los refugiados volvieran a Israel, un país pequeño y con una población de apenas seis millones de habitantes, generarían un desequilibrio étnico que acabaría con el carácter judío del Estado.

\section{Temporalidad en el exilio}

Burj Al-Barajneh es uno de esos suburbios a las afueras de Beirut, en el que los tanques de guerra y puestos de control con soldados al acecho sugieren que el alto al fuego puede interrumpirse en cualquier instante. El campamento para refugiados se encuentra controlado por facciones militares internas y los muros agujereados advierten que los militantes de Hamas y Fatah han intercambiado fuego en diversas ocasiones. La UNRWA, a pesar de sus atributos cuasiestatales, no posee jurisdicción sobre la población bajo su cuidado. Las marañas coloridas de cables eléctricos tendidas como enormes telarañas a lo largo y ancho de los callejones nos acompañan a lo largo del recorrido por Burj Al-Barajneh. Al óxido y basura que recubren el precario sistema de tuberías expuesto por todo el campamento, las autoridades libanesas responden impidiendo el paso de materiales para la mejora de la infraestructura en atención a mantener vivo el "respeto al derecho al retorno".

En Líbano se identifica a los habitantes de los campamentos de refugiados palestinos con base en el peligro simbólico que representan para la sociedad de acogida. El número de refugiados es tan grande que el delicado equilibrio sectario se encuentra en ebullición perma-

${ }^{7}$ La UNRWA ejerce su acción asistencial en Siria, Líbano, Jordania, Cisjordania y la franja de Gaza, "About UNRWA", en United Nations Relief and Works Agency for Palestine Refugees in the Near East (DE, 9 de mayo, 2012: http://www.unrwa.org/etemplate.php?id=47). 
nente. ${ }^{8}$ Por eso, en términos foucaultianos, se les somete continuamente a una "tecnología de cuidado y control" que implica la administración directa de su espacio y sus movimientos. ${ }^{9}$ Para las "personas fuera de lugar" se han institucionalizado una serie de medidas que llevan por fin último su vigilancia y exclusión de la sociedad de acogida. Sin embargo, las comunidades de refugiados palestinos, lejos de percibir su estatus de refugiado como una disfunción social, lo valoran y protegen como símbolo de la temporalidad en el exilio.

En Burj Al-Barajneh, cerca de 20,000 personas dependen casi por completo de los servicios básicos que proporciona la UNRWA. Nuha Nasser y Bahaa'eddine Hassoun, trabajadores sociales de la UNRWA para el desarrollo de la comunidad, nos hablan de la dificultad de acceder a los servicios que provee el gobierno libanés. Unos años atrás, a los refugiados palestinos no se les permitía trabajar en más de setenta profesiones, heredar o poseer títulos de propiedad. Nasser dice que se llegó al punto de que, cuando a los niños se les pedía que se dibujasen a sí mismos ejerciendo la profesión que deseaban hacer de grandes, la mayoría de los trazos hablaban de hombrecillos uniformados con emblemas de la UNRWA. Así, las etiquetas adheridas durante 150 las labores obligadas por su estatus temporal llegaron a ser constitutivas de su identidad.

${ }^{8}$ Muchos cristianos maronitas creen que la naturalización de los refugiados palestinos (tawtin) -casi el diez por ciento de la población- inclinaría la balanza del equilibrio sectario en favor de los musulmanes sunitas.

${ }^{9}$ Ver Liisa Malkki, "National Geographic: The Rooting of Peoples and the Territorialization of National Identity among Scholars and Refugees", en G. Eley y R. Suny (eds.), Becoming National: A Reader, 1996, Nueva York y Oxford, Oxford University Press, p. 444. Malkki argumenta que los refugiados viven en un estado perpetuo de liminalidad en el orden categórico de Estado-nación. Al constituir una aberración dentro de este orden, se les clasifica como población disfuncional, objeto de intervención terapéutica. En el caso palestino, la intervención puede entenderse de dos maneras: la más brutal, a manos de poderes difícilmente defendibles, o la legal, justificada por mandato internacional. Durante la Guerra civil (1975-1991), y en especial después de la salida de la Organización para la Liberación de Palestina (OLP), los civiles palestinos que habitaban en los campamentos sufrieron sucesivas masacres perpetradas por las milicias libanesas (la Falange maronita y Shi'a Amal) con la complacencia de los ejércitos sirio e israelí. Entre los episodios más cruentos de los asedios de los campos de refugiados se cuenta la masacre de Tal al-Za'tar (1975-6) y Sabra y Shatila (1982). 
Con su manera memorable de evocar recuerdos, Ayid describe uno de los tragos más amargos que tuvo que soportar durante los años en los que vivió en Cisjordania. "Los soldados israelíes llevaron a prisión a mi hijo mayor en tres ocasiones: a los trece, a los quince y a los diecisiete. La primera vez lo acusaron injustamente de lanzar explosivos a una patrulla. La segunda vez lo golpearon salvajemente en la cárcel" - he visto a la Historia en una bandera negra que camina y avanza como un bosque... "Era 1988; lo golpearon tanto que enfermó y tuvieron que transferirlo a un hospital. Al llegar ahí me dijeron: 'No conocemos a su hijo'. Pero yo estaba seguro de que él se encontraba internado en ese hospital, porque un pariente nuestro que trabajaba allí me dijo: 'en la habitación 214'; él lo vio ahí, con sus propios ojos. Y debido a que miembros de la Cruz Roja me acompañaban, los trabajadores del hospital me aseguraron que mi hijo nunca había ingresado. Permaneció internado dos semanas más y después lo llevaron de vuelta a prisión. Ahora es doctor y trabaja en un hospital aquí en Oslo".

Aunque el regreso a su tierra permanece como estímulo poderoso, para muchos refugiados la experiencia en el país de acogida altera su concepto de hogar y pertenencia. “¿Ayid, usted espera regresar algún día a Palestina?" -pregunté. "Mis hijos están disfrutando de su vida aquí. Todos son propietarios de su vivienda. Todos están casados. No creo que a estas alturas sea conveniente asentarme allá. Sin embargo, si trabajo unos años más aquí y luego me siento con ganas de morir, lo haría allá." Ya lo decía Mahmoud Darwish en "The Madness of Being Palestinian": frente al silencio de los países árabes y la apatía de Occidente, el palestino lo único que puede hacer es seguir reafirmando su identidad y defendiendo la totalidad de su sueño. No puede hacer otra cosa más que "volverse más palestino", más palestino hasta volver a su tierra de origen, más palestino hasta la muerte. ${ }^{10}$ "Ayid -continué- ¿usted cree que algún día se reconciliarán palestinos e israelíes?”

${ }^{10}$ Mahmoud Darwish, "The Madness of Being a Palestinian", en Journal of Palestine Studies, 1985, vol. 15, núm. 1, p. 141. 
"Si quieres la verdad, en el fondo, no lo acepto. Palestina es Palestina; desde el Mar [Mediterráneo] hasta el Río [Jordán] y fue tomada por la fuerza... fue tomada por la fuerza...", repite una segunda vez mientras se le atenúa la voz y el brillo de sus ojos se ve invadido por una profunda tristeza. Mi patria es esta centella, este relámpago en la tiniebla del porvenir...

Antes de abandonar la trastienda del Folketeatret le comenté a Ayid que mi experiencia con el pueblo palestino me llevó a apreciar su fuerte cohesión social y compromiso comunitario. "¿A qué cree usted que se debe?" "Es algo que viene desde dentro. No lo podemos cambiar Mi padre me decía 'esta es nuestra tierra'; yo dije a mis hijos 'esta es nuestra tierra'; y ellos dirán lo mismo a mis nietos. No hay que darse por vencidos". Y es que, para los integrantes del pueblo palestino, sean de primera o cuarta generación, afirmar su identidad es un acto de valor, una acción moral y una necesidad espiritual.

\section{Durante el último de los atardeceres en Tartús}

Caía la tarde en Kafar Sita cuando los niños comenzaron a entonar una melodía que provocaba una suerte de espontaneidad atemporal en el ambiente. Tan difuso era su encanto, que incluso el niño que se perfilaba como el pequeño fundamentalista entre sus compañeros -quien, en la playa, ejercía una reprimenda sobre todas las mujeres que desafiaban el código de vestimenta impuesto por la Ley islámicaconducía un coro que repetía al unísono una famosa canción mexicana, pronunciado cada letra con exquisito cuidado. Sin necesidad de recurrir a la labor de traducción de Qassem, "el cubano", el mensaje se transmitía íntegro; fluía con el maravilloso vocabulario inherente que no origina divisiones; el mismo que con una pequeñísima muestra confiere la capacidad para elevarse más allá de las fronteras impuestas por las identidades, hasta llenar de alegría - cielito lindo- los corazones.

Tal vez en un futuro -por el momento difícil de prever- pueda llegar a ser éste el mismo lenguaje que acorte la distancia abismal entre la realidad política y la satisfacción de las aspiraciones de los refugiados, 
construida sobre la base del derecho al retorno; el mismo que detenga la historia sobre una bandera blanca; que convierta en una actividad sin sentido sacar a relucir las fechas; que consuma el fuego que enciende la rebelión; que haga salir las palabras "hogar" y "tierra" del mundo ilusorio en el que se desgastan sin distinción; y, finalmente, que expulse de la lengua el consolidado significado de la añoranza.

Mientras tanto, merece la pena preguntarse qué sentido de esperanza podemos ofrecer a los palestinos hoy. El torbellino de manifestaciones de protesta social en Medio Oriente y Norte de África ha colocado a la región en la punta de la mira, al tiempo que el proceso de paz árabe-israelí permanece relegado a un segundo plano. A la ola de revueltas se suman reajustes políticos dentro de las cúpulas de poder, campañas electorales, guerras civiles, amenazas nucleares, recortes presupuestales, intereses geoestratégicos y sangrientos dictadores que se aferran a la silla presidencial, entre una interminable lista de situaciones coyunturales que desvían la atención del proceso de paz palestinoisraelí. Con este panorama, ¿qué asegura a los palestinos que, de llegar a estabilizarse el escenario regional, los impedimentos al proceso de paz dejarán de existir? ¿Qué razones hay para pensar que los gobiernos que emergen de la llamada "primavera árabe" se solidarizarán con la causa humanitaria palestina, sin convertirla nuevamente en un instrumento para la movilización de las masas o en un simple medio para asegurarse una base electoral, como acostumbraron hacerlo los regímenes que los movimientos opositores ahora se empeñan en derrocar? La frustración por vivir en medio del fuego cruzado, entre aspiraciones de justicia silenciada, sumidos en el olvido y el inmovilismo, pueden tristemente llegar a desencadenar nuevos episodios de violencia. 
La reproducción total o parcial de este artículo se podrá hacer si el ITAM otorga la autorización previamente por escrito. 